\title{
Composition, Antifungal, Phytotoxic, and Insecticidal Activities of Thymus kotschyanus Essential Oil
}

\author{
Ghader Ghasemi ${ }^{1}$, Abolfazl Alirezalu ${ }^{1, *}\left(\mathbb{D}\right.$, Youbert Ghosta ${ }^{2}$, Azadeh Jarrahi ${ }^{2}$, \\ Seyed Ali Safavi ${ }^{2}{ }^{(}$, Mahdi Abbas-Mohammadi ${ }^{3}$, Francisco J. Barba $\left.{ }^{4}{ }^{(}\right)$, Paulo E. S. Munekata ${ }^{5}$, \\ Rubén Domínguez ${ }^{5}$ and José $M$. Lorenzo ${ }^{5, *(D)}$ \\ 1 Department of Horticultural Sciences, Faculty of Agriculture, Urmia University, Urmia 5756151818, Iran; \\ gader.g1390@yahoo.com \\ 2 Department of Plant Protection, Faculty of Agriculture, Urmia University, Urmia 165-5715944931, Iran; \\ ghoosta@gmail.com (Y.G.); jarrahiazadeh@yahoo.com (A.J.); a.safavi@urmia.ac.ir (S.A.S.) \\ 3 Department of Phytochemistry, Medicinal Plants and Drugs Research Institute, Shahid Beheshti University, \\ Tehran 1983969411, Iran; mehdiamohamadi@ymail.com \\ 4 Nutrition and Food Science Area, Preventive Medicine and Public Health, Food Sciences, Toxicology and \\ Forensic Medicine Department, Faculty of Pharmacy, Universitat de València, Avda. Vicent Andrés Estellés, \\ s/n, 46100 Burjassot, València, Spain; francisco.barba@uv.es \\ 5 Centro Tecnológico de la Carne de Galicia, rúa Galicia n 4, Parque Tecnológico de Galicia, 16 San Cibrao das \\ Viñas, 32900 Ourense, Spain; paulosichetti@ceteca.net (P.E.S.M); rubendominguez@ceteca.net (R.D.) \\ * Correspondence: a.alirezalu@urmia.ac.ir (A.A.); jmlorenzo@ceteca.net (J.M.L.)
}

Academic Editors: Monika Waksmundzka-Hajnos and Miroslaw Hawryl

Received: 14 February 2020; Accepted: 2 March 2020; Published: 4 March 2020

\begin{abstract}
Essential oils (EOs) are some of the outstanding compounds found in Thymus that can exert antifungal, phytotoxic, and insecticidal activities, which encourage their exploration and potential use for agricultural and food purposes. The essential oils (EO) obtained from Thymus kotschyanus collected in the East Azerbaijan Province (Iran) were characterized using a gas chromatography-mass spectrometry (GC-MS) analysis. Thymol was the most important compound (60.48\%), although 35 other active compounds were identified in the EO. Significant amounts of carvacrol (3.08\%), $p$-cymene $(5.56 \%)$, and $\gamma$-terpinene $(6.67 \%)$ were found in the EO. The T. kotschyanus EO was tested against important phytopathogenic fungi (Botrytis cinerea, Aspergillus niger, and Penicillium expansum). The antifungal assay showed that the use of $\geq 500 \mathrm{ppm}$ of EO resulted in a fungicidal effect against all funguses tested. In a similar way, the use of $\geq 500 \mathrm{ppm}$ of EO inhibited the germination of all crop weed seeds (Amaranthus retroflexus L. and Panicum miliaceum L.) and their subsequent growth, which demonstrated its herbicidal effect. Finally, the insecticidal capacity of T. kotschyanus EO was also observed against selected insects (Oryzaephilus surinamensis and Sitophilus oryzae). O. surinamensis was more susceptible to the effect of $\mathrm{EO}\left(\mathrm{LC}_{50}=4.78 \mu \mathrm{L} / \mathrm{L}\right.$ air $)$ than $S$. oryzae $\left(\mathrm{LC}_{50}=13.20 \mu \mathrm{L} / \mathrm{L}\right.$ air $)$. The obtained results of the present study can provide new safe resources to the development of new products for the food, agriculture, and pharmaceutical industries.
\end{abstract}

Keywords: monoterpenes; thymol; $\gamma$-terpene; crop pests; post-harvest management

\section{Introduction}

The Genus Thymus L., family Labiatae, consists of more than 215 herbaceous perennial species mainly distributed in the Mediterranean region [1,2]. In Iran, fourteen species of Thymus L. are known [3]. Thymus kotschyanus represents one of the most diffused Thymus species. It is exploited mainly, but not only, in folk medicine to improve the digestive process and to treat respiratory disorders. Furthermore, its use as an aromatic ingredient, spice, or to prepare an herbal tea is 
well-known [2]. Aromatic and medicinal plants have a variety of biological compounds, including essential oils, alkaloids, coumarins, flavonoids, phenols, saponins, and tannins, which provide them with antibacterial, antifungal, and pesticide attributes [4]. Essential oils (EOs) represent a sub-category of secondary metabolites which are found in aromatic plants, known as natural and various compounds with significant attributes and which play a key role in protecting the plants via their antibacterial, antiviral, antifungal, and pesticide attributes [5]. These EOs are a complex mixture of substances that are present at different forms and concentrations. Monoterpenes, oxygenated monoterpenes, sesquiterpenes, and oxygenated sesquiterpenes are the predominant constituents, but phenolic compounds are also important components of some EOs [6]. The EO's chemical composition is varied, because it is affected by environmental conditions, ontogenetic, weather and temperature, pre and post-harvest, and genetic factors [7]. With regards to this, there are a significant variation in chemical compositions of the EOs of various Thymus species. A recent research found that the essential oil composition of T. kotschyanus contained $54.6 \%$ of thymol [8], while other authors found that the EOs of this species was composed by $41.4 \%$ of carvacrol and $19.6 \%$ of thymol [9]. Other Thymus species, such as T. carnosus, T. pubescens, and T. persicus, showed values of thymol between $14 \%$ and $36 \%$ [10-12]. In addition to thymol, in some of these species, authors also observed high contents of other compounds, such as p-cymene (21.3\%) [12], carvacrol (48.8\%) [11], and geraniol (9.4\%) [10].

On the other hand, several EOs and other plant extracts are also used as substitutes for synthetic additives in the food industry [13-15], by direct addition [16-20] or by applying as active packaging [21-23], to limit microbial and oxidation degradation of food [24-27].

Over the last decade, T. kotschyanus has gained popularity due to its potential applications, not only in the food industry but also in the pharmaceutical (ascertained antifungal, anti-inflammatory, antimicrobial, and expectorant properties) and cosmetic industries, as components of soaps, toothpastes, and perfumes [1,28-30]. In addition, the management of crop pests and diseases is a constant and necessary concern in agricultural and food industries. For instance, Botrytis cinerea, Penicillium expansum, and Aspergillus niger are among the most common worldwide post-harvest pathogens of fruits and vegetables [31].

However, synthetic pesticides, herbicides, and fungicides are contaminants introduced into the environment that can be extremely hazardous to the human body and agricultural products due to slow degradation and consequent persistence in the environment [32,33]. Moreover, excessive use of synthetic pesticides, herbicides, and fungicides has made pathogens and insects to be resistant to such chemicals $[34,35]$. In this line of thought, the search for environmentally friendly strategies to manage crop pests and diseases has become an interesting field of application for natural products [32,33]. Among the green strategies, the use of EOs is an appealing alternative to synthetic and toxic compounds commonly used in crop management and, for instance, as new antifungal agents [36]. Since some EOs from medicinal herbs exhibit phytotoxic activity, these natural sources can be explored for agricultural and food-processing purposes [4,37].

Essential oils (EOs) are some of the outstanding compounds found in Thymus L. that can exert antifungal, bactericidal, phytotoxic, antiparasitic, and insecticidal activities, which encourage their exploration and potential use for agricultural and food purposes [4,16,37-39]. In the last decades, EOs were also studied to evaluate their use in weed control and crop productivity (the so-called allelopathic effect) [40]. The compounds with such properties could be used for the biological control of plant pathogens and weeds as natural pesticides and herbicides with less destructive effects on the environment [41]. Different EOs obtained from some thyme species have demonstrated allelopathic effects and could be used to control and combat the growth of the weed species [42,43].

Although several Thymus species were studied and the chemical composition, antioxidant activity, and biological properties of their essential oils were determined $[29,44]$, few studies deal with the composition and biological activity of T. kotschyanus in North West Iran. Therefore, in the present study, the antioxidant, phytochemical, antifungal, phytotoxic, and insecticidal properties of some derivatives of T. kotschyanus grown in the North West of Iran were evaluated. 


\section{Results and Discussion}

\subsection{Phytochemical Characterization}

The amount of essential oil (EO) yielded by the Clevenger hydro-distillation method was 3.5\% (v/w) of dry weight, which had a color nuance ranging from light orange to yellow. GC-MS chromatogram and chemical compositions of EO are shown in Table 1 and Figure 1, respectively.

Table 1. Percentage chemical composition and retention indices of the essential oil of Thymus kotschyanus.

\begin{tabular}{|c|c|c|c|c|c|}
\hline No & Compounds & Tn & RI & RI-L & Percentage \\
\hline 1 & $\alpha$-Thujene & 3.98 & 926 & 925 & $1.38 \pm 0.01$ \\
\hline 2 & $\alpha$-Pinene & 4.11 & 934 & 932 & $0.96 \pm 0.00$ \\
\hline 3 & Camphene & 4.37 & 949 & 952 & $0.62 \pm 0.00$ \\
\hline 4 & $\beta$-Pinene & 4.86 & 978 & 978 & $0.53 \pm 0.00$ \\
\hline 5 & 3-Octanone & 4.97 & 984 & 984 & $0.16 \pm 0.00$ \\
\hline 6 & $\beta$-Myrcene & 5.07 & 990 & 991 & $1.36 \pm 0.01$ \\
\hline 7 & 3-Octanol & 5.16 & 995 & 994 & $0.15 \pm 0.00$ \\
\hline 8 & $\alpha$-Phellandrene & 5.37 & 1006 & 1006 & $0.27 \pm 0.00$ \\
\hline 9 & 3-Carene & 5.49 & 1011 & 1011 & $0.08 \pm 0.00$ \\
\hline 10 & $\alpha$-Terpinene & 5.62 & 1017 & 1017 & $2.1 \pm 0.01$ \\
\hline 11 & p-Cymene & 5.82 & 1026 & 1026 & $5.56 \pm 0.02$ \\
\hline 12 & Limonene & 5.89 & 1030 & 1030 & $0.52 \pm 0.00$ \\
\hline 13 & 1,8-Cineol & 5.95 & 1032 & 1033 & $2.82 \pm 0.02$ \\
\hline 14 & $\gamma$-Terpinene & 6.56 & 1060 & 1060 & $6.67 \pm 0.03$ \\
\hline 15 & cis-Sabinene hydroxide & 6.76 & 1069 & 1070 & $1.66 \pm 0.01$ \\
\hline 16 & $\alpha$-Terpinolen & 7.21 & 1090 & 1090 & $0.12 \pm 0.00$ \\
\hline 17 & trans-Sabinene hydrate & 7.48 & 1102 & 1104 & $0.57 \pm 0.00$ \\
\hline 18 & Camphor & 8.6 & 1148 & 1148 & $0.36 \pm 0.00$ \\
\hline 19 & Borneol & 9.18 & 1171 & 1173 & $1.82 \pm 0.01$ \\
\hline 20 & Terpinen-4-ol & 9.44 & 1182 & 1182 & $0.88 \pm 0.00$ \\
\hline 21 & $\alpha$-Terpineol & 9.79 & 1196 & 1195 & $0.17 \pm 0.00$ \\
\hline 22 & cis- $\alpha$-terpineol & 10.02 & 1205 & 1209 & $0.13 \pm 0.00$ \\
\hline 23 & Carvacrol methyl ether & 11.12 & 1247 & 1246 & $2.94 \pm 0.01$ \\
\hline 24 & Thymol & 12.84 & 1313 & 1311 & $60.48 \pm 0.78$ \\
\hline 25 & Carvacrol & 12.94 & 1317 & 1316 & $3.02 \pm 0.01$ \\
\hline 26 & Thymol acetate & 13.97 & 1358 & 1357 & $0.13 \pm 0.00$ \\
\hline 27 & E-Caryophyllene & 15.62 & 1424 & 1422 & $2.18 \pm 0.01$ \\
\hline 28 & Aromandendrene & 16.08 & 1443 & 1440 & $0.09 \pm 0.00$ \\
\hline 29 & $\alpha$-Humulene & 16.44 & 1458 & 1457 & $0.08 \pm 0.00$ \\
\hline 30 & $\gamma$-Muurolene & 16.99 & 1480 & 1479 & $0.09 \pm 0.00$ \\
\hline 31 & Virdiflorene & 17.45 & 1499 & 1497 & $0.13 \pm 0.00$ \\
\hline 32 & $\beta$-Bisabolene & 17.74 & 1512 & 1511 & $1.36 \pm 0.01$ \\
\hline 33 & $\delta$-Cadinene & 18.1 & 1527 & 1526 & $0.16 \pm 0.00$ \\
\hline 34 & (E)- $\alpha$-Bisabolene & 18.53 & 1545 & 1545 & $0.17 \pm 0.00$ \\
\hline 35 & Spathulenol & 19.42 & 1583 & 1582 & $0.08 \pm 0.00$ \\
\hline 36 & Caryophyllene oxide & 19.53 & 1588 & 1587 & $0.21 \pm 0.00$ \\
\hline
\end{tabular}

A total of 36 compounds were detected by GC-MS analysis, being thymol $(60.48 \%)$, $\gamma$-terpinene $(6.67 \%), p$-cymene $(5.56 \%)$, and carvacrol (3.02\%), as well as 1,8-cineol (2.82\%) and E-caryophyllene $(2.18 \%)$ as the main components. The extraction yield of T. kotschyanus EO is in the range of values reported for Thyme species, which can vary in the range of 0.8-2.6\% [45-50]. Moreover, among 14 Thymus samples from Iran studied by Tohidi et al. [51], EO yield varied from $0.29 \%$ (T. fedtschenkoi) to $3.87 \%$ (T. migricus). 
The yield of EO and thymol content found in this study were significantly higher compared to other previous studies evaluating T. kotschyanus. Therefore, T. kotschyanus collected from the Shabestar region could be identified as a new thymol chemotype. For instance, other authors found variable amounts in T. kotschyanus that ranges from 1.1\% in plants collected in Yarz (Iran) [52] to 54.66\% in plants collected in the highlands of Bojnurd (Iran) at an altitude of $1700 \mathrm{~m}$ [8]. In addition, Tohidi et al. [53] analyzed the EOs of ten Thymus species from different areas of Iran and reported that thymol contents ranged from $12.4 \%$ (EO of T. fedtschenkoi) to $79.74 \%$ (EO of T. migricus).

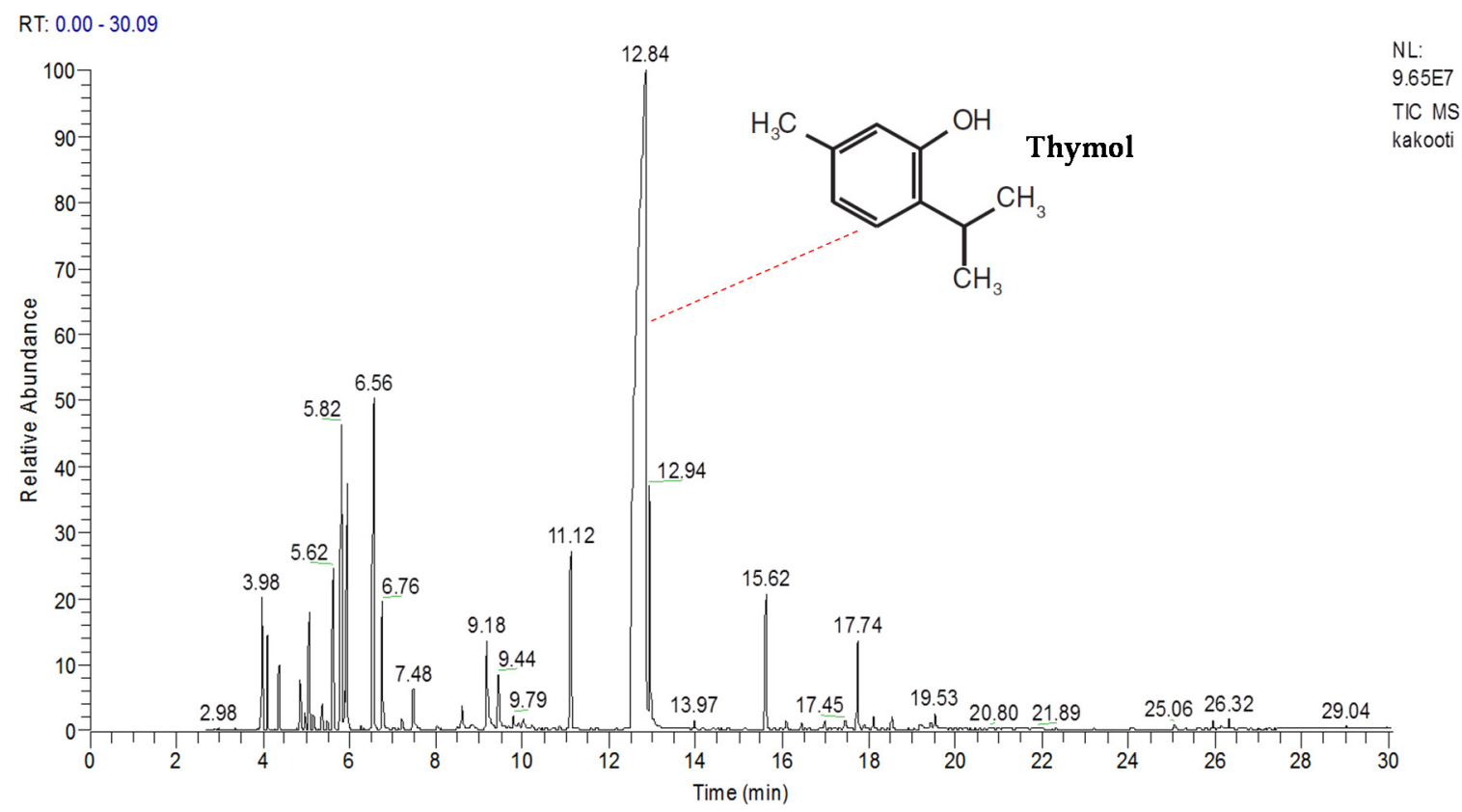

Figure 1. Gas chromatography-mass spectrometry chromatograms of Thymus kotschyanus essential oil (EO) from Shabestar, East Azerbaijan, Iran.

\subsection{Antifungal Activity}

The antifungal activity of EOs against mycelial growth is shown in Figure 2. Among the fungal strains tested, B. cinerea (Figure $3 \mathrm{~A}$ ) was the most susceptible fungus, and it was completely inhibited by all EO treatments. In the cases of $A$. niger (Figure 3B) and P. expansum (Figure 3C), mycelial growth was reduced at $250 \mathrm{ppm}$, being completely inhibited at concentrations of $\geq 500 \mathrm{ppm}$ (fungicidal effect). In addition, the effects of EOs at $250 \mathrm{ppm}$ were considered fungistatic for P. expansum and A. niger that were partially inhibited.

Some components of the EO, such as thymol, $\gamma$-terpinene, and carvacrol, display strong antifungal activity [53-57]. Particularly for thymol, a monoterpene phenolic compound, previous studies indicated an important effect against the growth of important fruit and food-spoiling fungi, such as A. niger, Alternaria alternata, B. cinerea, Fusarium oxysporum, and Rhizopus oryzae, that are [58-62]. In a similar way as the results obtained by us, other studies observed that thymol and carvacrol exhibit an important antifungal activity against postharvest pathogens Botrytis cinerea [63] and also against spoilage yeasts in wine [64]. Additionally, other research found that carvacrol inhibits the growth of Penicillium expansum spores, which agree with our results [65]. The protective effect of T. kotschyanus EO can be explained by irreversible damage to fungi membrane and the consequent leakage of the cytoplasmic contents [64], although the effects of other minor components should not be overlooked. 
Control

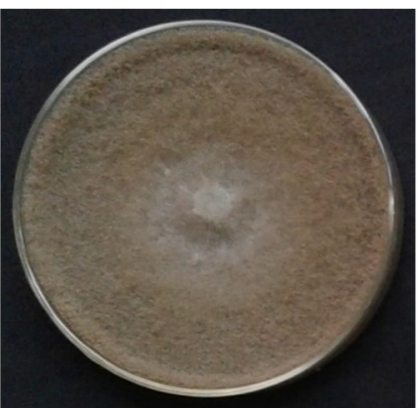

\section{A}

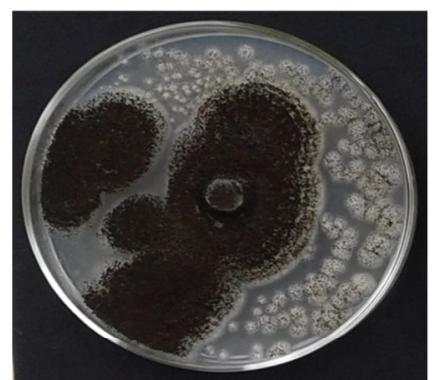

C

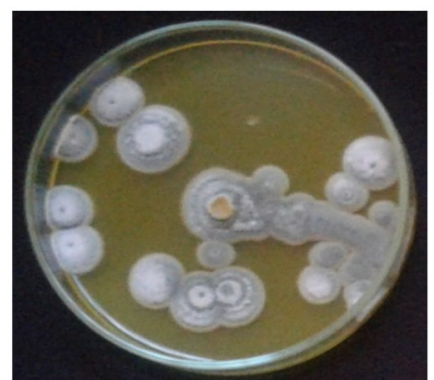

$250 \mu L_{L}^{-1}$
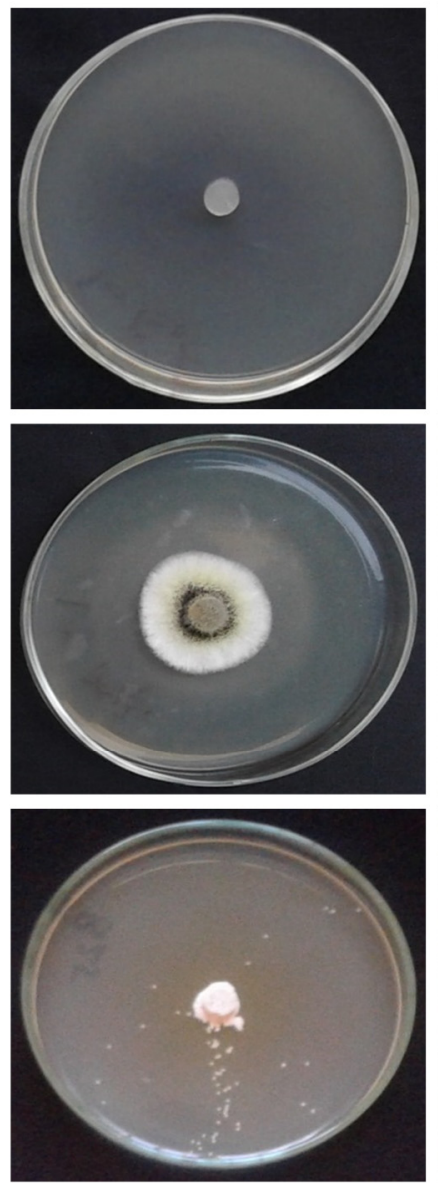

$\geq 500 \mu \mathrm{LL}^{-1}$
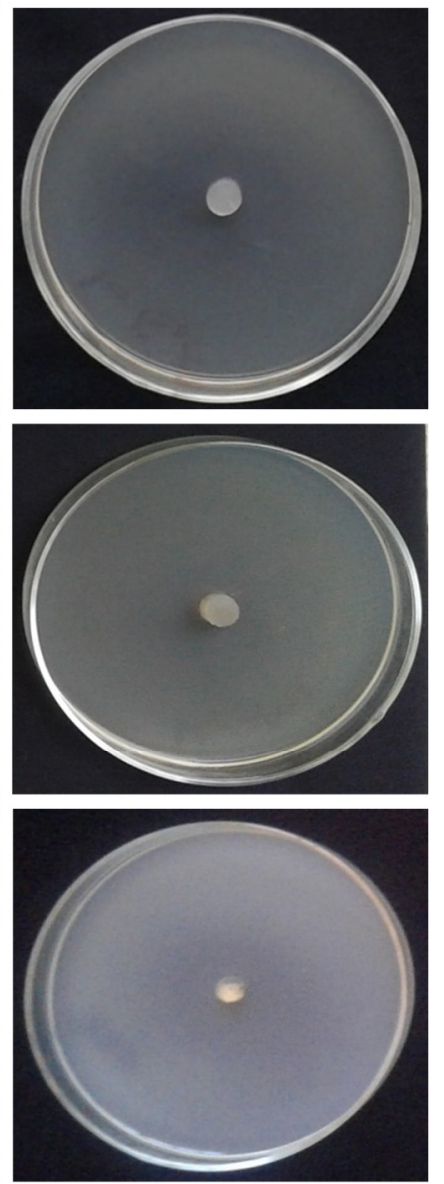

Figure 2. Antifungal activity of different concentration of T. kotschyanus EO on Botrytis cinerea (A), Penicillium expansum (B), and Aspergillus niger (C).

\subsection{Phytotoxic Activity}

The effect of EOs on weeds germination indices is shown in Table 2. In both weed species, germination and growth indices were affected by T. kotschyanus EO treatments. The final germination percentage (GP) varied significantly $(p<0.01)$ among the different EO concentrations used. For example, seed germination of $A$. retroflexus (Figure 4A) and P. miliaceum (Figure 4B) were completely inhibited when the concentrations exceeded $500 \mathrm{ppm}$. Likewise, the percentage germination of $A$. retroflexus was $81.33 \%$ and $0 \%$ for control and essential oils more than 500 ppm, respectively. For P. miliaceum, such index was $92.00 \%$ and $0 \%$ for control and EO more than 500 ppm, respectively. Moreover, mean germination time was significantly $(p<0.01)$ influenced by $T$. kotschyanus EO concentration. 

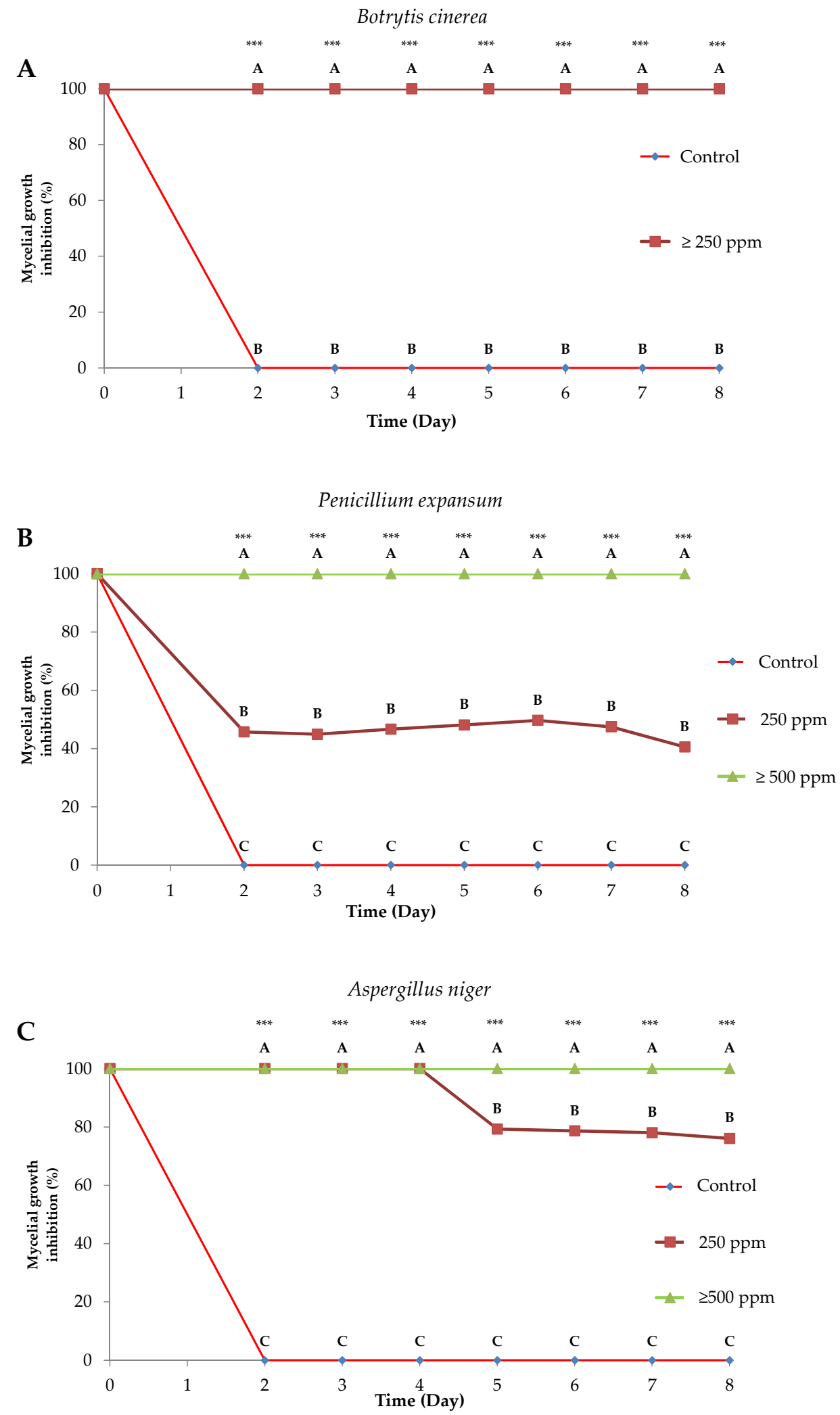

Figure 3. Evolution of mycelial growth inhibition (\%) (mean \pm standard error) of Botrytis cinerea (A), Penicillium expansum (B), and Aspergillus niger (C) by different concentrations of T. kotschyanus EO (ppm). A-C mean values not followed by a common letter differ significantly ( ${ }^{* * *}$ significant at $\left.p<0.001\right)$. 
Table 2. Influence of various concentrations of T. kotschyanus essential oil in seed germination indices of $A$. retroflexus and P. miliaceum at the end of incubation time. GP: germination percentage, MGT: mean germination time, GRI: germination rate index, RL: root length, ShL: shoot length, SLL: seedling length, FW: fresh weight, VI: vigor index, and T50: the time to reach $50 \%$ germination.

\begin{tabular}{|c|c|c|c|c|c|c|c|c|c|}
\hline Treatments & GP (\%) & MGT (day) & GRI & RL (cm) & ShL (cm) & SLL (cm) & FW (mg) & VI & T50 \\
\hline \multicolumn{10}{|c|}{ Amaranthus retroflexus } \\
\hline Control & $81.33 \pm 2.0$ & $3.22 \pm 0.31$ & $6.50 \pm 0.13$ & $1.54 \pm 0.12$ & $1.52 \pm 0.00$ & $3.05 \pm 0.13$ & $0.02 \pm 0.00$ & $248.33 \pm 16.81$ & $2.57 \pm 0.01$ \\
\hline $250 \mathrm{ppm}$ & $50.67 \pm 4.0$ & $4.70 \pm 0.28$ & $2.86 \pm 0.35$ & $0.45 \pm 0.12$ & 0.00 & $0.46 \pm 0.13$ & $0.01 \pm 0.00$ & $23.52 \pm 8.44$ & $4.17 \pm 0.29$ \\
\hline $500 \mathrm{ppm}$ & 0.00 & 0.00 & 0.00 & 0.00 & 0.00 & 0.00 & 0.00 & 0.00 & 0.00 \\
\hline 750 ppm & 0.00 & 0.00 & 0.00 & 0.00 & 0.00 & 0.00 & 0.00 & 0.00 & 0.00 \\
\hline 1000 ppm & 0.00 & 0.00 & 0.00 & 0.00 & 0.00 & 0.00 & 0.00 & 0.00 & 0.00 \\
\hline 1500 ppm & 0.00 & 0.00 & 0.00 & 0.00 & 0.00 & 0.00 & 0.00 & 0.00 & 0.00 \\
\hline LSD & 5.25 & 0.45 & 0.43 & 0.19 & 0.016 & 0.20 & 0.01 & 19.3 & 0.33 \\
\hline Prob & $* * *$ & $* * *$ & $* * *$ & $* * *$ & $* * *$ & $* * *$ & $* * *$ & $* * *$ & $* * *$ \\
\hline \multicolumn{10}{|c|}{ Panucum miliaceum } \\
\hline Control & $92 \pm 4.00$ & $2.52 \pm 0.08$ & $9.65 \pm 0.28$ & $5.54 \pm 1.09$ & $3.23 \pm 0.27$ & $8.78 \pm 1.36$ & $0.12 \pm 0.03$ & $803.67 \pm 91.0$ & $1.86 \pm 0.03$ \\
\hline $250 \mathrm{ppm}$ & $88 \pm 4.00$ & $3.83 \pm 0.15$ & $6.30 \pm 0.11$ & $1.06 \pm 0.16$ & $0.95 \pm 0.10$ & $2.01 \pm 0.12$ & $0.02 \pm 0.00$ & $176.44 \pm 2.1$ & $3.06 \pm 0.05$ \\
\hline $500 \mathrm{ppm}$ & 0.00 & 0.00 & 0.00 & 0.00 & 0.00 & 0.00 & 0.00 & 0.00 & 0.00 \\
\hline $750 \mathrm{ppm}$ & 0.00 & 0.00 & 0.00 & 0.00 & 0.00 & 0.00 & 0.00 & 0.00 & 0.00 \\
\hline 1000 ppm & 0.00 & 0.00 & 0.00 & 0.00 & 0.00 & 0.00 & 0.00 & 0.00 & 0.00 \\
\hline 1500 ppm & 0.00 & 0.00 & 0.00 & 0.00 & 0.00 & 0.00 & 0.00 & 0.00 & 0.00 \\
\hline LSD & 5.75 & 0.17 & 0.34 & 1.23 & 0.30 & 1.48 & 0.02 & 106.7 & 0.06 \\
\hline Prob & $* * *$ & $* * *$ & $* * *$ & $* * *$ & $* * *$ & $* * *$ & $* * *$ & $* * *$ & $* * *$ \\
\hline
\end{tabular}

Data represent means of three replicates compared by Duncan's multiple range test (DMRT) at $p<0.01 .{ }^{* * *}$ Significant at $(p<0.001)$. 

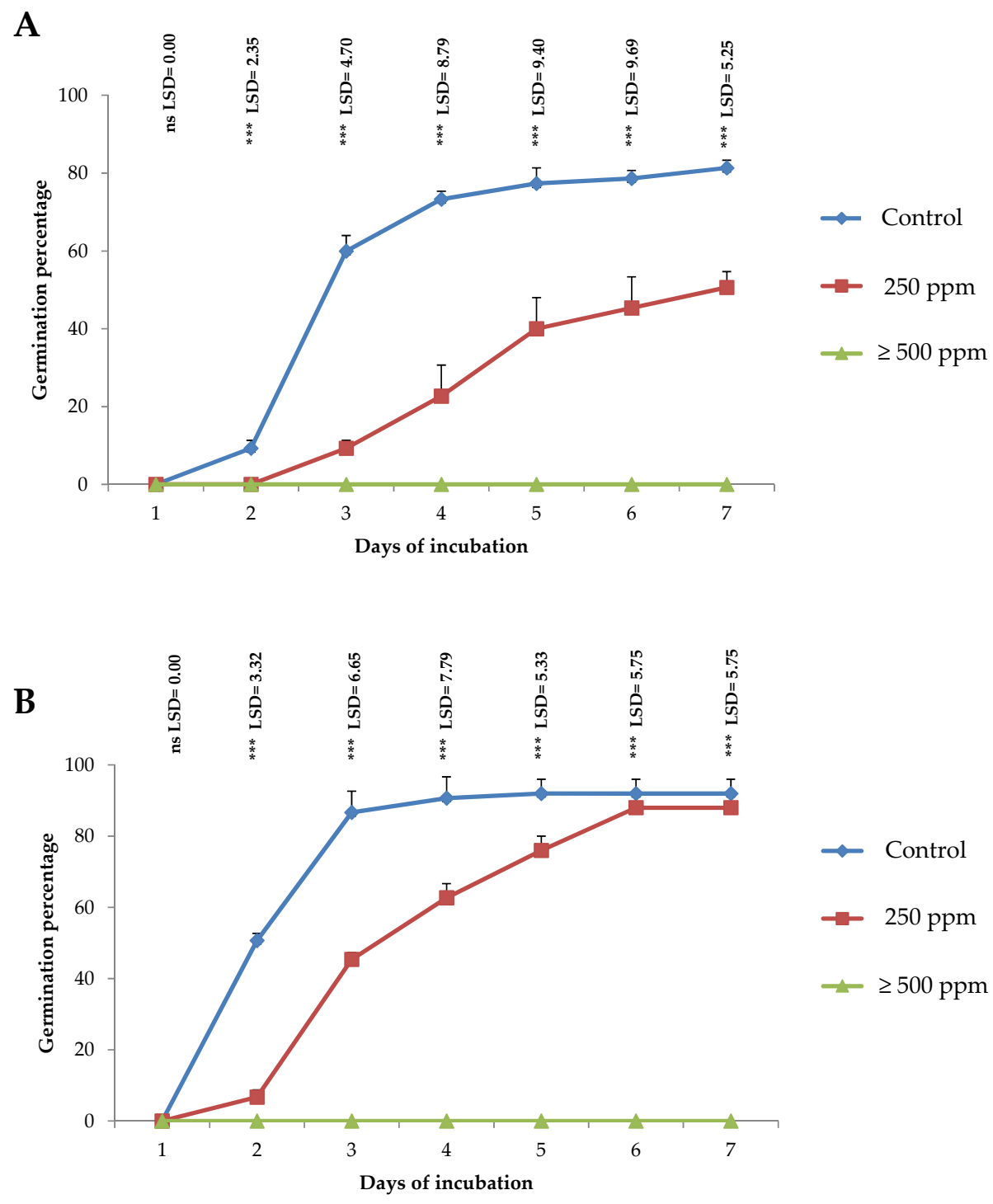

Figure 4. Effect of different concentrations of T. kotschyanus EO $(\mu \mathrm{L} / \mathrm{L})$ on the cumulative germination (mean \pm standard error) of Amaranthus retroflexus (A) and Panicum miliaceum (B). The least significant difference (LSD) indicates the differences between factors.

The GRI was significantly $(p<0.01)$ influenced by EO concentration, being the highest value found for control (6.50 and 9.65 units for A. retroflexus and P. miliaceum, respectively), and the lowest was obtained from EO treatments with 500, 750, 1000, and $1500 \mathrm{ppm}$ ( 0.00 units) for both $A$. retroflexus and P. miliaceum. A similar outcome was obtained for root length (RL) and shoot length (ShL). The seeds treated with T. kotschyanus EO displayed lower mean values than obtained in the control. The complete inhibition of root and shoot lengths were observed for seeds treated with $\geq 500 \mathrm{ppm}$ of $T$. kotschyanus EO.

Statistically significant differences $(p<0.01)$ among treatments were also observed in the seedling length (SLL) in both weeds. The highest length was observed in control $(3.05$ and $8.87 \mathrm{~cm})$, while the lowest values were obtained after the exposition of seeds to more than $500 \mathrm{ppm}$ of EO $(0.00 \mathrm{~cm})$ for A. retroflexus and P. miliaceum, respectively. The EOs decreased $(p<0.01)$ the SLL in a concentration-dependent manner, according to the weeds.

Moreover, it was also found that several concentrations of EOs had a significant effect $(p<0.01)$ on the fresh weight (FW) of seedlings. FW of samples treated with EOs were significantly lower than control for both weeds. Likewise, the vigor index (VI) was affected by EO concentration in both weeds. While the highest VI index was obtained in control (248.33 and 803.67 units for A. retroflexus 
and P. miliaceum, respectively), the lowest means values were observed in treatments with more than $500 \mathrm{ppm}$ (0.00 units) of EO. The time to achieve 50\% germination (T50 index) varied between the treatments for both studied species. The T50 index increased from 2.57 (control) to 4.17 (250 ppm) days for A. retroflexus seeds and from 1.86 (control) to 3.06 (250 ppm) days. Seeds treated with more than 500 ppm of T. kotschyanus EO did not germinate. The results obtained for T. kotschyanus EO phytotoxic activity are in agreement with other studies in scientific literature. An experiment with four Thymus daenensis ecotypes collected in Iran indicated that applying between 400 and $600 \mu \mathrm{L} / \mathrm{L}$ of EO was associated with complete inhibition of $A$. retroflexus seed GP, which consequently reduced the shoot and root fresh weight [66]. In the same line, the EO extracted from Thymus vulgaris displayed one of the lowest ED50 (concentration that causes 50\% inhibition of seed germination; $0.16 \mathrm{~g} / \mathrm{L}$ ) values to inhibit the germination of $A$. retroflexus seeds among selected essential oils (lemon balm, sage, and tansy, for instance) [67].

The allelopathic effect of T. kotschyanus EO on A. retroflexus and P. miliaceum seeds could be explained by the individual activity of monoterpenes. A study about the phytotoxic effect of pure thymol (10 mg/Petri dish) reported GP of $0.00 \%$ and root growth of $0.00 \%$ in [68]. Likewise, the treatment with $\gamma$-terpinene inhibited the GP (76.5 vs. 32.0 and $21.3 \%$ for control and 10 and $20 \mu \mathrm{L}$, respectively) and seedling root growth (28.9 vs. 22.0 and $14.5 \mathrm{~mm}$ for control and 10 and $20 \mu \mathrm{L}$, respectively) of A. retroflexus seeds [69].

Moreover, seems reasonable to consider that these two monoterpenes are the main compounds associated with T. kotschyanus EO allelopathic activity due to low phytotoxic activity reported for p-cymene on A. retroflexus, Chenopodium album, and Rumex crispus seeds [68]. Although the inhibitory mechanism exerted by terpenes on weed seeds remains unclear, previous studies reported relevant effects on cellular proliferation, induction of oxidative stress, and inhibition of DNA synthesis on weed seeds after terpene treatment $[70,71]$.

\subsection{Insecticidal Activity}

The T. kotschyanus EO was lethal for both insect species (O. surinamensis and S. oryzae) used in the experiments. O. surinamensis was more susceptible to the effect of EOs than S. oryzae, wherein the values of $\mathrm{LC}_{50}$ were 4.78 and $13.20 \mu \mathrm{L} / \mathrm{L}$ air, respectively (Table 3).

Moreover, $\mathrm{LT}_{50}$ values highlighted that the EOs killed O. surinamensis faster than S. oryzae. Cumulative mortality of O. surinamensis (Figure 5A) and S. oryzae (Figure 5B) increased daily. Half the population of $O$. surinamensis adults died within 1.57 days, and 95\% of insects were killed within 9.17 days after exposure to EO vapors. However, 50 percent and 95 percent of adult rice weevils were killed after 2.36 and 14.60 days of treatment, respectively (Table 4 and Figure 6).

These results are in agreement with data reported by other authors. For instance, the fumigant toxicity effects of commercial thyme EO and selected terpenes, particularly $p$-cymene and thymol, were evaluated against S. oryzae [72]. The authors obtained LC $_{50}$ and $\mathrm{LC}_{95}$ concentrations of 63.9 and $89.5 \mu \mathrm{L} / \mathrm{L}$ air for thyme EO, respectively. Regarding the individual terpenes, $p$-cymene displayed lower $\mathrm{LC}_{50}$ and $\mathrm{LC}_{95}$ concentrations ( 25 and $39 \mu \mathrm{L} / \mathrm{L}$ air, respectively) than those obtained for thymol (69 and $174 \mu \mathrm{L} / \mathrm{L}$ air, respectively). A similar fumigant toxicity effect of thyme EO was reported against Callosobruchus maculatus and Sitophilus granaries (relevant pests in the storage of legumes and wheat). In this case, the EO extracted from T. daenensis Celak displayed $\mathrm{LC}_{50}$ concentrations of 4.22 and $6.55 \mu \mathrm{L} / \mathrm{L}$ air for C. maculatus and S. granaries, respectively. The authors also obtained the $\mathrm{LC}_{90}$ concentrations for C. maculatus and $S$. granaries ( 8.21 and $8.73 \mu \mathrm{L} / \mathrm{L}$ air, respectively). 
Table 3. Lethal concentration values of T. kotschyanus essential oil on O. surinamensis and S. oryzae.

\begin{tabular}{|c|c|c|c|c|c|c|}
\hline Insect & $\mathrm{LC}_{50}\left(\mu \mathrm{L} \cdot \mathrm{L}^{-1}\right)$ & $\mathrm{LC}_{95}\left(\mu \mathrm{L} \cdot \mathrm{L}^{-1}\right)$ & Slope \pm SE & Intercept $\pm \mathrm{SE}$ & $x^{2}(\mathrm{df}=3)$ & $p$-Value \\
\hline O. surinamensis & $\begin{array}{c}4.78 \\
(4.12-5.51)\end{array}$ & $\begin{array}{c}17.98 \\
(13.63-27.63)\end{array}$ & $2.86 \pm 0.34$ & $-1.94 \pm 0.26$ & 2.04 & 0.57 \\
\hline S. oryzae & $\begin{array}{c}13.2 \\
(10.08-17.29)\end{array}$ & $\begin{array}{c}150.22 \\
(90.73-320.93)\end{array}$ & $1.56 \pm 0.18$ & $-1.75 \pm 0.22$ & 1.83 & 0.61 \\
\hline
\end{tabular}

Table 4. Lethal time values of T. kotschyanus essential oil on O. surinamensis and S. oryzae.

\begin{tabular}{|c|c|c|c|c|c|c|}
\hline Insect & $\mathrm{LT}_{50}$ (days) & $\mathrm{LT}_{95}$ (days) & Slope \pm SE & Intercept $\pm \mathrm{SE}$ & $x^{2}(\mathrm{df}=3)$ & $p$-Value \\
\hline O. surinamensis & $\begin{array}{c}1.57 \\
(1.26-1.91)\end{array}$ & $\begin{array}{c}9.17 \\
(6.64-14.62)\end{array}$ & $2.14 \pm 0.23$ & $-0.42 \pm 0.12$ & 1.73 & 0.63 \\
\hline S. oryzae & $\begin{array}{c}2.36 \\
(1.93-2.89)\end{array}$ & $\begin{array}{c}14.6 \\
(10.12-25.22)\end{array}$ & $2.08 \pm 0.23$ & $-0.78 \pm 0.13$ & 2.47 & 0.48 \\
\hline
\end{tabular}


A

\section{O. surinamensis}

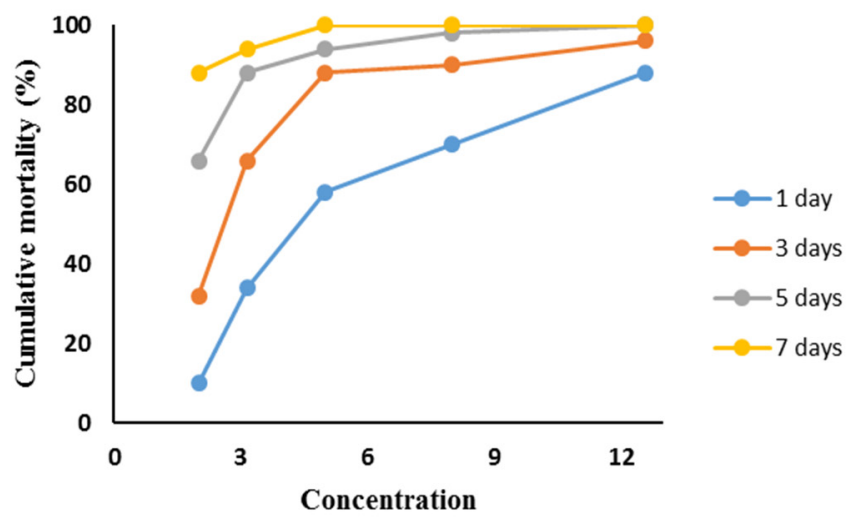

B

\section{S. oryzae}

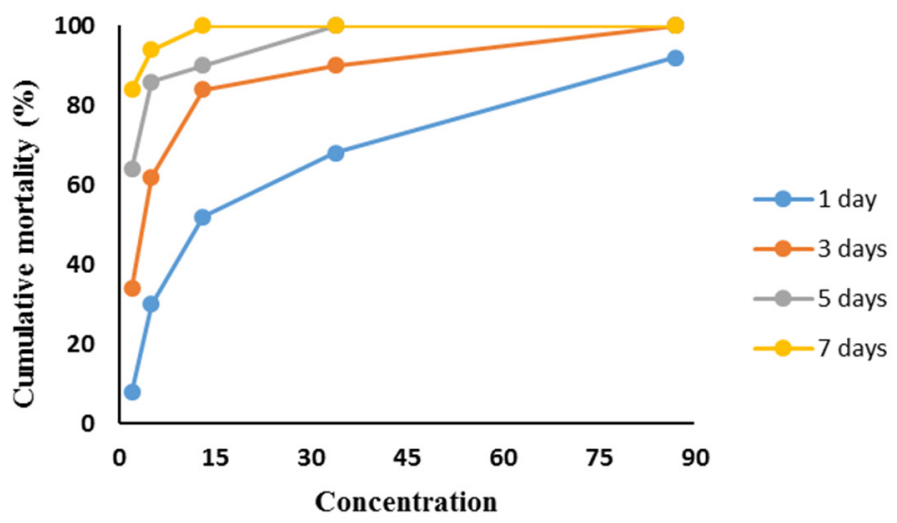

Figure 5. Cumulative mortality of stored pests (A: O. surinamensis and B: S. oryzae.exposed) to different concentrations of $T$. kotschyanus essential oil ( $\mu \mathrm{L} / \mathrm{L}$ air).

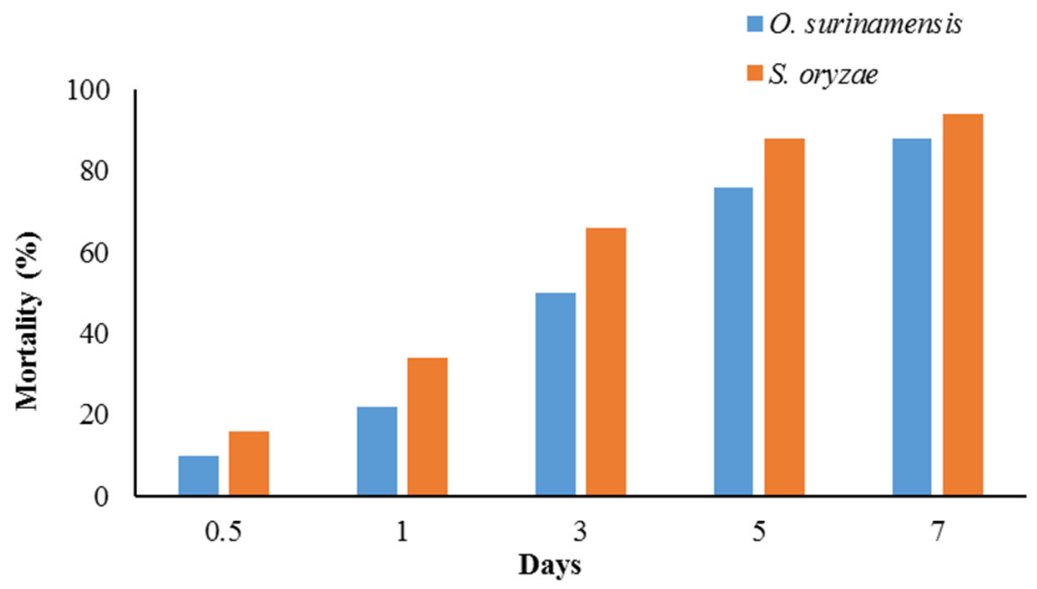

Figure 6. Evolution of pest mortality (\%) exposed to $3 \mu \mathrm{L} / \mathrm{L}$ air of $T$. kotschyanus essential oil.

The key role of T. kotschyanus EO compounds in the mortality of crop pests is also associated with impairment of important molecular pathways. Particularly for thymol, it was reported that this terpene can influence the GABA-gated chloride channel, which causes hyperexcitation of the central nervous system and can lead to convulsions and death. Another related effect of thymol exposure is modulation of a tyramine receptors cascade that eventually blocks the octopamine receptors and 
undermines neurological insect functions [73]. Finally, our results illustrated that T. kotschyanus has an insecticidal activity against insect pests.

\section{Materials and Methods}

\subsection{Plant Materials}

Aerial parts of Thymus kotschyanus plants (voucher number: UHDH-101) in the flowering stage were taken from the Shabestar Region in the East Azerbaijan Province, Iran in 2016. Having a classically semi-arid climate and at the altitude of $1352 \mathrm{~m}$ above the sea level (Latitude: $38^{\circ} 19^{\prime} \mathrm{N}$; Longitude: $45^{\circ} 18^{\prime} \mathrm{E}$ ), this region has a high precipitation rate that often takes place throughout the autumn and winter, whereas there is little rainfall in the summer.

\subsection{Extraction of Essential Oil}

Aerial parts of T. kotschyanus were harvested and dried at room temperature, preventing them from taking light. Dried leaves (20 g) were subjected to hydrodistillation through a Clevenger instrument (Urmia University, Urmia, Iran) for $3 \mathrm{~h}$. The resulting EO was poured into screw-capped vials and maintained in darkness at $4{ }^{\circ} \mathrm{C}$ for further analysis.

\subsection{GC and GC-MS Analysis}

The analysis of the oil was performed using an Agilent gas chromatograph (GC-FID) (Agilent Technologies, Santa Clara, CA, USA) with a DB-5-fused silica column $(30 \mathrm{~m} \times 0.25 \mathrm{~mm}$; $0.25 \mu \mathrm{m}$ film thickness). Nitrogen was used as the gas carrier at a constant flow of $1.1 \mathrm{~mL} / \mathrm{min}$. The oven temperature was programmed from 60 to $250{ }^{\circ} \mathrm{C}$ at $5{ }^{\circ} \mathrm{C} / \mathrm{min}$ and then isothermaled for $10 \mathrm{~min}$. The injector and FID temperatures were set at $250^{\circ} \mathrm{C}$ and $280^{\circ} \mathrm{C}$, respectively. The injection volume was $0.1 \mathrm{~mL}$. Samples were injected by splitting, and the split ratio was 1:100. GC-MS analysis was carried out on a Thermoquest Finnigan Trace GC-MS instrument equipped with a DB- 5 column (30 $\mathrm{m} \times 0.25 \mathrm{~mm} ; 0.25 \mu \mathrm{m}$ film thickness) programmed as above, with helium as the carrier gas with a flow rate of $1.1 \mathrm{~mL} / \mathrm{min}$ and a split ratio of 1:50. The MS operating parameters were: ionization voltage, $70 \mathrm{eV}$ and ion source temperature, $200{ }^{\circ} \mathrm{C}$. Identification of the compounds was performed by comparison of the retention indexes (relative to a homologue $C_{6}-C_{24} n$-alkane series) obtained in the same column with those of reference compounds. Additionally, each mass spectra obtained was compared with those from the usual electronic libraries [74,75]. Relative area percentages obtained from GC were used for quantification of the components.

\subsection{Fungal Isolates}

Three post-harvest pathogens fungal isolates, Bot-245 g (Botrytis cinerea Pers.), Pen-653mb (Penicillium expansum Link), and As-88ma (Aspergillus niger Tiegh.), purchased from the fungal culture collection of the Plant Pathology Department, Urmia University (Urmia, Iran) were used in our experiments. The pathogenicity of fungal isolates was previously confirmed (data not shown). Fungal isolates were grown in potato dextrose agar (PDA) medium at $25 \pm 2{ }^{\circ} \mathrm{C}$. Only actively growing colonies were used in bioassays [76].

\subsection{In vitro Antifungal Assays}

The antifungal activity of the T. kotschyanus essential oil was evaluated through the poison food medium method. Different concentrations of T. kotschyanus essential oil (0, 250, 500, 750, 1000, and $1500 \mu \mathrm{L} / \mathrm{L})$ were prepared in sterile water containing Tween $80(0.5 \%, v / v)$ and aseptically added to sterile, cooled, molten potato dextrose agar (PDA Merck, Darmstadt, Germany) medium ( $45^{\circ} \mathrm{C}$ ). The resulting mixture (EO plus medium) were instantly dispensed onto sterilized glass petri plates (90 mm diameter, $20 \mathrm{~mL}$ each) and allowed to solidify under aseptic conditions. A mycelial disk 
(6-mm-diameter) of the tested fungi, taken from the margins of the actively growing cultures, was placed upside-down at the center of the petri plates.

Inoculated petri plates were incubated in darkness at $25 \pm 2{ }^{\circ} \mathrm{C}$. The control was composed of $0.5 \%$ Tween 80 in sterile water. Four replicates were used for each treatment, and all the experiments were repeated twice. Antifungal activity of essential oil was measured taking into account the percentage of the mycelial growth inhibition (MGI), calculated by the following the formula [77]:

$$
\operatorname{MGI}(\%)=\frac{(d c-d t)}{d c} \times 100
$$

where $d c$ was the colony growth diameter in the control and $d t$ represented the diameter of colony growth in the treatment.

In the case of no visible growth detected after the incubation with the essential oil, and in order to determine fungistatic and/or fungicidal effects of the essential oil against the tested fungi, the inoculated discs were transferred to new PDA plates and incubated again at $25 \pm 2{ }^{\circ} \mathrm{C}$ for more than $72 \mathrm{~h}$. If mycelial growth was restarted in PDA medium, the effect was considered fungistatic; otherwise, it was considered fungicidal.

\subsection{Phytotoxic Activity}

Ripe seeds of Amaranthus retroflexus L. (redroot pigweed) and Panicum miliaceum L. (millet) collected from the North West of Iran (West Azerbaijan Province) on September, 2016 were used to investigate the phytotoxic effect exhibited by the EO. Seeds were stored in paper bags for a span of four weeks at room temperature. The viability of the seeds and their germinability were checked prior to the experiments. Surfaces of seeds were sterilized through a two-step procedure (rinse for $30 \mathrm{~s}$ with $70 \%$ ethyl-alcohol and a subsequent treatment with a $10 \%$ sodium hypochlorite solution for $20 \mathrm{~min}$ ), then washed three times with sterile distilled water, and finally, air-dried in aseptic conditions under a laminar hood. Fifty seeds from each weed were placed in Petri dishes containing two layers of filter-paper (Whatman No. 2). To make exact concentrations of EO in water $(0,250,500,750$, 1000 , and $1500 \mu \mathrm{L} / \mathrm{L}$ ), first a stock of EO in dimethyl sulfoxide (DMSO)/water (1\%, $v / v)$ was prepared. Ultimately, $10 \mathrm{~mL}$ of each concentration was poured into the petri dishes. In the controls, $1 \%$ DMSO in water was used. Each treatment had five replicates, and all the experiments were replicated twice. The petri dishes containing seeds were sealed by plastic paraffin film tape. Then, petri dishes were kept in a germinator set at $25^{\circ} \mathrm{C}$ with a $16-\mathrm{h}$ photoperiod of $28-36 \mathrm{mM} / \mathrm{m}^{2} \mathrm{~s}$.

In this experiment, germination percentage (GP); mean germination time (MGT); germination rate index (GRI); vigor index (VI); root, shoot, and seedling lengths (RL, ShL, and SLL, respectively); and T50 index were measured. The GP was expressed as the ratio of germinated seed to the total of the seeds. The MGT and GRI were calculated using the following formula [78]:

$$
\text { MGT }=\frac{\sum n \cdot d}{N}
$$

where $n$ is the number of seeds germinated on each day, $d$ is the days from the beginning of the germination test, and $N$ represents the final germinated seeds. The GRI:

$$
\mathrm{GRI}=\sum \frac{\text { (number of germinated seeds since } \mathrm{n}-1)}{n}
$$

where $n$ represents the days of incubation. At the end of the incubation, root, shoot, and seedling lengths were also measured, and the seed vigor index (VI) was obtained using the equation [79]:

$$
V I=[S L L(\mathrm{~cm}) x G P]
$$

The T50 value was calculated in terms of days needed for germination of $50 \%$ of the seeds. 


\subsection{Insecticidal Activity}

The fumigant toxicity of T. kotschyanus EO was assessed using two model insect species, which are mainly the infesting of food products during their storage, namely the saw-toothed grain beetle (Oryzaephilus surinamensis) and the so-called rice weevil (Sitophilus oryzae). LC L0 $_{50}$ (median lethal concentration) and $\mathrm{LT}_{50}$ (median lethal time) values were used as parameters to calculate the insecticidal strength of the EO. After preliminary bioassays, 6-cm-diameter disks of filter papers (Whatman No. 1) were impregnated with different concentrations of the essential oil $(2-87 \mu \mathrm{L} / \mathrm{L}$ air for $S$. oryzae and $2-12.6 \mu \mathrm{L} / \mathrm{L}$ air for $O$. surinamensis) without any solvent. The disks were mounted on the underside of tightly screwed caps of $250 \mathrm{~mL}$ glass vials. Ten newly emerged adults of each insect were introduced into each vial. Combinations of different concentrations and exposure times (1-7 days) were replicated five times. In the controls, only filter papers were used. Vials were kept in darkness, 70\% $\pm 5 \% \mathrm{RH}$ and $28 \pm 1{ }^{\circ} \mathrm{C}$. Mortality percentage was recorded at 24 -h intervals until 7 days. Insects with no reaction after physical stimulation (leg or antennal movements) were considered as dead.

\subsection{Statistical Analysis}

Statistical analyses of the data (antifungal and phytotoxic activity) were performed using MSTAT-C statistical software (Michigan State University, East Lansing, MI, USA), and means were separated by DMRT at 0.01 probability level. In the case of insecticidal activity, all the experiments were replicated five times. Data were analyzed using SPSS V22.0 software (IBM, Armonk, NY, USA).

\section{Conclusions}

The analysis of T. kotschyanus EO (yield around 3.5\%) composition collected in the Shabestar Region (Iran) revealed that thymol is the main compound, followed by $\gamma$-terpinene and $p$-cymene. Moreover, our results also showed that $T$. kotschyanus EOs can be considered as an efficient natural compound to control post-harvest fungal diseases ( $A$. niger and P. expansum; fungicidal effect at concentration $\geq 500 \mathrm{ppm}$ ); weeds (A. retroflexus and P. miliaceum; $\geq 500 \mathrm{ppm}$ ); and harmful insects (O. surinamensis and S. oryzae). Therefore, taking into account the several issues related to the harmful effects on the environment and on the health associated with synthetic pesticides, and the remarkable fungicidal properties of T. kotschyanus active components, the EO evaluated in the present study can be certainly considered as a good alternative in the post-harvest pest management.

Author Contributions: Conceptualization, G.G., A.A., Y.G., M.A.-M., and J.M.L.; methodology, G.G., A.A., Y.G., and M.A.-M.; formal analysis, G.G., A.A., Y.G., A.J., S.A.S., and M.A.-M.; writing-original draft preparation, G.G., A.A., Y.G., and M.A.-M.; and writing—review and editing, Y.G., A.J., S.A.S., F.J.B., P.E.S.M., R.D., and J.M.L. All authors have read and agreed to the published version of the manuscript.

Funding: This research received no external funding.

Acknowledgments: This research was supported by Urmia University, Urmia, Iran. Paulo E. S. Munekata acknowledges a postdoctoral fellowship support from the Ministry of Economy and Competitiveness (MINECO, Spain) “Juan de la Cierva” program (FJCI-2016-29486).

Conflicts of Interest: The authors declare no conflict of interest.

\section{References}

1. Lorenzo, J.M.; Mousavi-Khaneghah, A.; Gavahian, M.; Marszałek, K.; Es, I.; Munekata, P.E.S.; Ferreira, I.C.F.R.; Barba, F.J. Understanding the potential benefits of thyme and its derived products for food industry and consumer health: From extraction of value-added compounds to the evaluation of bioaccessibility, bioavailability, anti-inflammatory, and antimicrobial activities. Crit. Rev. Food Sci. Nutr. 2019, 59, 2879-2895. [CrossRef] [PubMed]

2. Morales, R. The history, botany and taxonomy of the genus Thymus. In Thyme the Genus Thymus-Medicinal and Aromatic Plants; Stahl-Biskup, E., Saez, F., Eds.; CRC Press: Boca Raton, FL, USA, 2002; pp. 1-43. ISBN 9780203216859. 
3. Moradi, P.; Falsafi, T.; Saffari, N.; Rahimi, E.; Momtaz, H.; Hanedi, B. Chemical composition and antimicrobial effects of Thymus daenensis on Helicobacter pylori. Biosci. Biotechnol. Res. Commun. 2017, 10, 139-144. [CrossRef]

4. Adorjan, B.; Buchbauer, G. Biological properties of essential oils: An updated review. Flavour Fragr. J. 2010, 25, 407-426. [CrossRef]

5. Bakkali, F.; Averbeck, S.; Averbeck, D.; Idaomar, M. Biological effects of essential oils-A review. Food Chem. Toxicol. 2008, 46, 446-475. [CrossRef]

6. Miguel, M.G. Antioxidant and anti-inflammatory activities of essential oils: A short review. Molecules 2010, 15, 9252-9287. [CrossRef]

7. Chou, S.T.; Lai, C.C.; Lai, C.P.; Chao, W.W. Chemical composition, antioxidant, anti-melanogenic and anti-inflammatory activities of Glechoma hederacea (Lamiaceae) essential oil. Ind. Crops Prod. 2018, 122, 675-685. [CrossRef]

8. Zhiani, R.; Dolatabadi, S.; Imani, H.; Moradi, M.; Emrani, S. A Comparison of the chemical composition of flowering shoot Thymus kotschyanus and Thymus vulgaris by using GC-mass and antimicrobial effects of the bacteria Staphylococcus aureus and Pseudomonas aeruginosa. J. Essent. Oil-Bear. Plants 2016, 19, 1639-1647. [CrossRef]

9. Sefidkon, F.; Jamzad, Z.; Yavari-Behrouz, R.; Nouri Shargh, D. Essential oil composition of Thymus kotschyanus boiss. And hohen from Iran. J. Essent. Oil Res. 1999, 11, 459-460. [CrossRef]

10. Sefidkon, F.; Dabiri, M.; Mirmostafa, S.A. The essential oil of Thymus persicus (Ronniger ex Rech. f.) Jalas from Iran. J. Essent. Oil Res. 2002, 14, 351-352. [CrossRef]

11. Sefidkon, F.; Askari, F.; Ghorbanli, M. Essential oil composition of Thymus pubescens Boiss. et Kotschy ex Celak from Iran. J. Essent. Oil Res. 2002, 14, 116-117. [CrossRef]

12. Sefidkon, F.; Askari, F.; Mirmostafa, S.A. The essential oil of Thymus carnosus Boiss. From Iran. J. Essent. Oil Res. 2001, 13, 192-193. [CrossRef]

13. Fernandes, R.P.P.; Trindade, M.A.; Tonin, F.G.; Lima, C.G.; Pugine, S.M.P.; Munekata, P.E.S.; Lorenzo, J.M.; de Melo, M.P. Evaluation of antioxidant capacity of 13 plant extracts by three different methods: cluster analyses applied for selection of the natural extracts with higher antioxidant capacity to replace synthetic antioxidant in lamb burgers. J. Food Sci. Technol. 2016, 53, 451-460. [CrossRef] [PubMed]

14. Fernandes, R.P.P.; Trindade, M.A.; Lorenzo, J.M.; Munekata, P.E.S.; de Melo, M.P. Effects of oregano extract on oxidative, microbiological and sensory stability of sheep burgers packed in modified atmosphere. Food Control. 2016, 63, 65-67. [CrossRef]

15. Domínguez, R.; Gullón, P.; Pateiro, M.; Munekata, P.E.S.; Zhang, W.; Lorenzo, J.M. Tomato as potential source of natural additives for meat industry. A Review. Antioxidants 2020, 9, 73. [CrossRef]

16. Pateiro, M.; Barba, F.J.; Domínguez, R.; Sant'Ana, A.S.; Mousavi Khaneghah, A.; Gavahian, M.; Gómez, B.; Lorenzo, J.M. Essential oils as natural additives to prevent oxidation reactions in meat and meat products: A review. Food Res. Int. 2018, 113, 156-166. [CrossRef]

17. Munekata, P.E.S.; Domínguez, R.; Franco, D.; Bermúdez, R.; Trindade, M.A.A.; Lorenzo, J.M. Effect of natural antioxidants in Spanish salchichón elaborated with encapsulated n-3 long chain fatty acids in konjac glucomannan matrix. Meat Sci. 2017, 124, 54-60. [CrossRef]

18. Lorenzo, J.M.; González-Rodríguez, R.M.; Sánchez, M.; Amado, I.R.; Franco, D. Effects of natural (grape seed and chestnut extract) and synthetic antioxidants (buthylatedhydroxytoluene, BHT) on the physical, chemical, microbiological and sensory characteristics of dry cured sausage "chorizo". Food Res. Int. 2013, 54, 611-620. [CrossRef]

19. Fernandes, R.P.P.; Trindade, M.A.; Tonin, F.G.; Pugine, S.M.P.; Lima, C.G.; Lorenzo, J.M.; de Melo, M.P. Evaluation of oxidative stability of lamb burger with Origanum vulgare extract. Food Chem. 2017, 233, 101-109. [CrossRef]

20. Fernandes, R.P.P.; Trindade, M.A.; Lorenzo, J.M.; de Melo, M.P. Assessment of the stability of sheep sausages with the addition of different concentrations of Origanum vulgare extract during storage. Meat Sci. 2018, 137, 244-257. [CrossRef]

21. Domínguez, R.; Barba, F.J.; Gómez, B.; Putnik, P.; Bursać Kovačević, D.; Pateiro, M.; Santos, E.M.; Lorenzo, J.M. Active packaging films with natural antioxidants to be used in meat industry: A review. Food Res. Int. 2018, 113, 93-101. [CrossRef] 
22. Pateiro, M.; Domínguez, R.; Bermúdez, R.; Munekata, P.E.S.; Zhang, W.; Gagaoua, M.; Lorenzo, J.M. Antioxidant active packaging systems to extend the shelf life of sliced cooked ham. Curr. Res. Food Sci. 2019, 1, 24-30. [CrossRef]

23. Lorenzo, J.M.; Batlle, R.; Gómez, M. Extension of the shelf-life of foal meat with two antioxidant active packaging systems. LWT-Food Sci. Technol. 2014, 59, 181-188. [CrossRef]

24. Pateiro, M.; Vargas, F.C.; Chincha, A.A.I.A.; Sant'Ana, A.S.; Strozzi, I.; Rocchetti, G.; Barba, F.J.; Domínguez, R.; Lucini, L.; do Amaral Sobral, P.J.; et al. Guarana seed extracts as a useful strategy to extend the shelf life of pork patties: UHPLC-ESI/QTOF phenolic profile and impact on microbial inactivation, lipid and protein oxidation and antioxidant capacity. Food Res. Int. 2018, 114, 55-63. [CrossRef] [PubMed]

25. Cunha, L.C.M.; Monteiro, M.L.G.; Lorenzo, J.M.; Munekata, P.E.S.; Muchenje, V.; de Carvalho, F.A.L.; Conte-Junior, C.A. Natural antioxidants in processing and storage stability of sheep and goat meat products. Food Res. Int. 2018, 111, 379-390. [CrossRef] [PubMed]

26. Domínguez, R.; Pateiro, M.; Gagaoua, M.; Barba, F.J.; Zhang, W.; Lorenzo, J.M. A comprehensive review on lipid oxidation in meat and meat products. Antioxidants 2019, 8, 429. [CrossRef] [PubMed]

27. Echegaray, N.; Gómez, B.; Barba, F.J.; Franco, D.; Estévez, M.; Carballo, J.; Marszałek, K.; Lorenzo, J.M. Chestnuts and by-products as source of natural antioxidants in meat and meat products: A review. Trends Food Sci. Technol. 2018, 82, 110-121. [CrossRef]

28. Giordani, R.; Hadef, Y.; Kaloustian, J. Compositions and antifungal activities of essential oils of some Algerian aromatic plants. Fitoterapia 2008, 79, 199-203. [CrossRef]

29. Hazzit, M.; Baaliouamer, A.; Veríssimo, A.R.; Faleiro, M.L.; Miguel, M.G. Chemical composition and biological activities of Algerian Thymus oils. Food Chem. 2009, 116, 714-721. [CrossRef]

30. Mahmoudi, M.; Morteza-Semnani, K.; Mojra, E. Anti-inflammatory and antinociceptive activity of Thymus pubescens extract. Fitoterapia 2008, 79, 361-365. [CrossRef]

31. Xiao, C.L.; Rogers, J.D. A Postharvest fruit rot in d'Anjou pears caused by Sphaeropsis pyriputrescens sp. nov. Plant. Dis. 2004, 88, 114-118. [CrossRef]

32. Fenoll, J.; Sabater, P.; Navarro, G.; Vela, N.; Pérez-Lucas, G.; Navarro, S. Abatement kinetics of 30 Sulfonylurea herbicide residues in water by photocatalytic treatment with semiconductor materials. J. Environ. Manage. 2013, 130, 361-368. [CrossRef] [PubMed]

33. Olaniran, A.O.; Igbinosa, E.O. Chlorophenols and other related derivatives of environmental concern: Properties, distribution and microbial degradation processes. Chemosphere 2011, 83, 1297-1306. [CrossRef]

34. Janisiewicz, W.J.; Korsten, L. Biological control of postharvest diseases of fruits. Annu. Rev. Phytopathol. 2002, 40, 411-441. [CrossRef] [PubMed]

35. Yu, C.; Zeng, L.; Sheng, K.; Chen, F.; Zhou, T.; Zheng, X.; Yu, T. $\gamma$-Aminobutyric acid induces resistance against Penicillium expansum by priming of defence responses in pear fruit. Food Chem. 2014, 159, $29-37$. [CrossRef] [PubMed]

36. Marín, S.; Sanchis, V.; Ramos, A.J. Plant products in the control of mycotoxins and mycotoxigenic fungi on food commodities. In Natural Products in Plant Pest Management; Dubey, N.K., Ed.; CABI: Oxfordshire, UK, 2010; pp. 21-41. ISBN 9781845936716.

37. Edris, A.E. Pharmaceutical and therapeutic potentials of essential oils and their individual volatile constituents: A review. Phyther. Res. 2007, 21, 308-323. [CrossRef]

38. Hashemi, S.M.B.; Mousavi Khaneghah, A.; Koubaa, M.; Barba, F.J.; Abedi, E.; Niakousari, M.; Tavakoli, J. Extraction of essential oil from Aloysia citriodora Palau leaves using continuous and pulsed ultrasound: Kinetics, antioxidant activity and antimicrobial properties. Process. Biochem. 2018, 65, 197-204. [CrossRef]

39. Giacometti, J.; Bursać Kovaćević, D.; Putnik, P.; Gabrić, D.; Bilušić, T.; Krešić, G.; Stulić, V.; Barba, F.J.; Chemat, F.; Barbosa-Cánovas, G.; et al. Extraction of bioactive compounds and essential oils from mediterranean herbs by conventional and green innovative techniques: A review. Food Res. Int. 2018, 113, 245-262. [CrossRef]

40. Singh, H.P.; Batish, D.R.; Kohli, R.K. Allelopathic interactions and allelochemicals: New possibilities for sustainable weed management. CRC. Crit. Rev. Plant. Sci. 2003, 22, 239-311. [CrossRef]

41. Kong, C.H.; Xu, X.H.; Zhang, M.; Zhang, S.Z. Allelochemical tricin in rice hull and its aurone isomer against rice seedling rot disease. Pest. Manag. Sci. 2010, 66, 1018-1024. [CrossRef] 
42. Ben El Hadj Ali, I.; Bahri, R.; Chaouachi, M.; Boussaïd, M.; Harzallah-Skhiri, F. Phenolic content, antioxidant and allelopathic activities of various extracts of Thymus numidicus Poir. organs. Ind. Crops Prod. 2014, 62, 188-195. [CrossRef]

43. Ben El Hadj Ali, I.; Chaouachi, M.; Bahri, R.; Chaieb, I.; Boussaïd, M.; Harzallah-Skhiri, F. Chemical composition and antioxidant, antibacterial, allelopathic and insecticidal activities of essential oil of Thymus algeriensis Boiss. et Reut. Ind. Crops Prod. 2015, 77, 631-639. [CrossRef]

44. Dob, T.; Dahmane, D.; Benabdelkader, T.; Chelghoum, C. Studies on the essential oil composition and antimicrobial activity of Thymus algeriensis Boiss. et Reut. Int. J. Aromather. 2006, 16, 95-100. [CrossRef]

45. Sefidkon, F.; Dabiri, M.; Rahimi-Bidgoly, A. The effect of distillation methods and stage of plant growth on the essential oil content and composition of Thymus kotschyanus Boiss. and Hohen. Flavour Fragr. J. 1999, 14, 405-408. [CrossRef]

46. Rasooli, I.; Mirmostafa, S.A. Bacterial susceptibility to and chemical composition of essential oils from Thymus kotschyanus and Thymus persicus. J. Agric. Food Chem. 2003, 51, 2200-2205. [CrossRef] [PubMed]

47. Nickavar, B.; Mojab, F.; Dolat-Abadi, R. Analysis of the essential oils of two Thymus species from Iran. Food Chem. 2005, 90, 609-611. [CrossRef]

48. Toroglu, S. In vitro antimicrobial activity and antagonistic effect of essential oils from plant species. J. Environ. Biol. 2007, 28, 551-559.

49. Amiri, H. Essential oils composition and antioxidant properties of three Thymus species. Evidence-Based Complement. Altern. Med. 2012, 2012, 1-8. [CrossRef]

50. Nabavi, S.M.; Marchese, A.; Izadi, M.; Curti, V.; Daglia, M.; Nabavi, S.F. Plants belonging to the genus Thymus as antibacterial agents: From farm to pharmacy. Food Chem. 2015, 173, 339-347. [CrossRef]

51. Tohidi, B.; Rahimmalek, M.; Arzani, A. Essential oil composition, total phenolic, flavonoid contents, and antioxidant activity of Thymus species collected from different regions of Iran. Food Chem. 2017, 220, $153-161$. [CrossRef]

52. Khanavi, M.; Hajimehdipoor, H.; Emadi, F.; Khandani, N.K. Essential Oil Compositions of Thymus kotschyanus Boiss. obtained by hydrodistillation and microwave oven distillation. J. Essent. Oil-Bear. Plants 2013, 16, 117-122. [CrossRef]

53. Razzaghi-Abyaneh, M.; Shams-Ghahfarokhi, M.; Yoshinari, T.; Rezaee, M.-B.; Jaimand, K.; Nagasawa, H.; Sakuda, S. Inhibitory effects of Satureja hortensis L. essential oil on growth and aflatoxin production by Aspergillus parasiticus. Int. J. Food Microbiol. 2008, 123, 228-233. [CrossRef] [PubMed]

54. Giweli, A.; Džamić, A.M.; Soković, M.; Ristić, M.S.; Marin, P.D. Antimicrobial and antioxidant activities of essential oils of Satureja thymbra growing wild in Libya. Molecules 2012, 17, 4836-4850. [CrossRef] [PubMed]

55. Adams, S.; Kunz, B.; Weidenbürner, M. Mycelial deformations of Cladosporium herbarum due to the Application of Eugenol or Carvacrol. J. Essent. Oil Res. 1996, 8, 535-540. [CrossRef]

56. Adam, K.; Sivropoulou, A.; Kokkini, S.; Lanaras, T.; Arsenakis, M. Antifungal activities of Origanum vulgare subsp. hirtum, Mentha spicata, Lavandula angustifolia, and Salvia fruticosa essential oils against human pathogenic fungi. J. Agric. Food Chem. 1998, 46, 1739-1745. [CrossRef]

57. Ocak, I.; Çelik, A.; Özel, M.Z.; Korcan, E.; Konuk, M. Antifungal activity and chemical composition of essential oil of Origanum Hypericifolium. Int. J. Food Prop. 2012, 15, 38-48. [CrossRef]

58. Abbaszadeh, S.; Sharifzadeh, A.; Shokri, H.; Khosravi, A.R.; Abbaszadeh, A. Antifungal efficacy of thymol, carvacrol, eugenol and menthol as alternative agents to control the growth of food-relevant fungi. J. Mycol. Med. 2014, 24, e51-e56. [CrossRef]

59. Šegvić Klarić, M.; Kosalec, I.; Mastelić, J.; Piecková, E.; Pepeljnak, S. Antifungal activity of thyme (Thymus vulgaris L.) essential oil and thymol against moulds from damp dwellings. Lett. Appl. Microbiol. 2006, 44,36-42. [CrossRef]

60. Mathur, A.; Singh, R.; Yousuf, S.; Bhardwaj, A.; Satish, K. Antifungal activity of some plant extracts against clinical pathogens. Adv. Appl. Sci. Res. 2011, 2, 260-264.

61. Campaniello, D.; Corbo, M.R.; Sinigaglia, M. Antifungal activity of eugenol against Penicillium, Aspergillus, and Fusarium species. J. Food Prot. 2010, 73, 1124-1128. [CrossRef]

62. Morcia, C.; Malnati, M.; Terzi, V. In vitro antifungal activity of terpinen-4-ol, eugenol, carvone, 1,8-cineole (eucalyptol) and thymol against mycotoxigenic plant pathogens. Food Addit. Contam. Part A 2012, 29, 415-422.

63. Zhang, J.; Ma, S.; Du, S.; Chen, S.; Sun, H. Antifungal activity of thymol and carvacrol against postharvest pathogens Botrytis cinerea. J. Food Sci. Technol. 2019, 56, 2611-2620. [CrossRef] [PubMed] 
64. Chavan, P.S.; Tupe, S.G. Antifungal activity and mechanism of action of carvacrol and thymol against vineyard and wine spoilage yeasts. Food Control. 2014, 46, 115-120. [CrossRef]

65. Hassan, B.; Soumya, E.; Moulay, S.; Mounyr, B.; Saad, I.K. Antifungal activity and physico-chemical surface properties of the momentaneously exposed Penicillium expansum spores to carvacrol. Res. J. Microbiol. 2016, 11, 178-185.

66. Kashkooli, A.B.; Saharkhiz, M.J. Essential Oil Compositions and Natural Herbicide Activity of Four Denaei Thyme (Thymus daenensis Celak.) Ecotypes. J. Essent. Oil Bear. Plants 2014, 17, 859-874. [CrossRef]

67. Synowiec, A.; Kalemba, D.; Drozdek, E.; Bocianowski, J. Phytotoxic potential of essential oils from temperate climate plants against the germination of selected weeds and crops. J. Pest. Sci. 2017, 90, 407-419. [CrossRef]

68. Kordali, S.; Cakir, A.; Ozer, H.; Cakmakci, R.; Kesdek, M.; Mete, E. Antifungal, phytotoxic and insecticidal properties of essential oil isolated from Turkish Origanum acutidens and its three components, carvacrol, thymol and p-cymene. Bioresour. Technol. 2008, 99, 8788-8795. [CrossRef]

69. Kordali, S.; Cakir, A.; Sutay, S. Inhibitory effects of monoterpenes on seed germination and seedling growth. Z. Naturforsch. C. 2007, 62, 207-214. [CrossRef]

70. Mutlu, S.; Atici, Ö.; Esim, N.; Mete, E. Essential oils of catmint (Nepeta meyeri Benth.) induce oxidative stress in early seedlings of various weed species. Acta Physiol. Plant. 2011, 33, 943-951. [CrossRef]

71. Nishida, N.; Tamotsu, S.; Nagata, N.; Saito, C.; Sakai, A. Allelopathic effects of volatile monoterpenoids produced by Salvia leucophylla: Inhibition of cell proliferation and DNA synthesis in the root apical meristem of Brassica campestris seedlings. J. Chem. Ecol. 2005, 31, 1187-1203. [CrossRef]

72. Lee, B.-H.; Choi, W.-S.; Lee, S.-E.; Park, B.-S. Fumigant toxicity of essential oils and their constituent compounds towards the rice weevil, Sitophilus oryzae (L.). Crop. Prot. 2001, 20, 317-320. [CrossRef]

73. Rattan, R.S. Mechanism of action of insecticidal secondary metabolites of plant origin. Crop. Prot. 2010, 29, 913-920. [CrossRef]

74. Davies, N.W. Gas chromatographic retention indices of monoterpenes and sesquiterpenes on methyl silicon and Carbowax 20M phases. J. Chromatogr. A 1990, 503, 1-24. [CrossRef]

75. Sparkman, O.D. Identification of essential oil components by gas chromatography/quadrupole mass spectroscopy Robert P. Adams. J. Am. Soc. Mass Spectrom. 2005, 16, 1902-1903. [CrossRef]

76. Jiménez, M.; Mateo, J.; Hinojo, M.; Mateo, R. Sugars and amino acids as factors affecting the synthesis of fumonisins in liquid cultures by isolates of the Gibberella fujikuroi complex. Int. J. Food Microbiol. 2003, 89, 185-193. [CrossRef]

77. Tian, J.; Ban, X.; Zeng, H.; Huang, B.; He, J.; Wang, Y. In vitro and in vivo activity of essential oil from dill (Anethum graveolens L.) against fungal spoilage of cherry tomatoes. Food Control 2011, 22, 1992-1999. [CrossRef]

78. Ellis, R.H.; Roberts, E.H. The quantification of ageing and survival in orthodox seeds. Seed Sci. Technol. 1981, 9, 373-409.

79. Kulkarni, M.G.; Street, R.A.; Van Staden, J. Germination and seedling growth requirements for propagation of Dioscorea dregeana (Kunth) Dur. and Schinz-A tuberous medicinal plant. S. Afr. J. Bot. 2007, 73, 131-137. [CrossRef]

Sample Availability: Samples of Thymus kotschyanus essential oil are available from the authors.

(C) 2020 by the authors. Licensee MDPI, Basel, Switzerland. This article is an open access article distributed under the terms and conditions of the Creative Commons Attribution (CC BY) license (http://creativecommons.org/licenses/by/4.0/). 